\title{
PROCESSOS COMUNICACIONAIS
}

\section{INTERNOS E SUAS IMPLICAÇÕES}

\section{NA ORGANIZAÇÃO}

\section{INNER COMMUNICATION PROCESSES AND THEIR IMPLICATIONS FOR THE ORGANIZATION}

ELIANE ZANLUCHII

Mestre em Administração pela Universidade do Vale do Rio dos Sinos

(Unisinos) e bacharel em Comunicação Social. Habilitação em Publicidade e Propaganda pela mesma instituição.Professora da Pós-graduação Latu Sensu em Comunicação e Marketing em Organizações Cooperativas da Univates - Centro Universitário do Vale do Taquari - e do curso de Gestão Empreendedora da Faculdade de Tecnologia FTEC Brasil.

Rua Dr. Montauri, 188/802 - Bento Gonçalves - RS - CEP 95700-000

E-mail: elizanluchi@hotmail.com

\section{CLÁ UIO DAMACENA}

Doutor em Administração pela Universidade de Córdoba (Espanha). Professor e pesquisador do Programa de Mestrado em Administração da Universidade do Vale do Rio dos Sinos (UNISINOS). Coordenador do MBA em Marketing Estratégico da Unisinos. Rua Vicente da Fontoura, $110 / 801$ - Novo Hamburgo - RS - CEP 93410-650

E-mail: damacena@unisinos.br

MARTIN DE LA MARTINIËRE PETROLL Mestrando no Programa de Pós-Graduação em Administração pela Escola de Administração da Universidade Federal do Rio Grande do Sul (PPGA/EA/UFRGS) e bacharel em Administração de Empresas pela Universidade do Vale do Rio dos Sinos (Unisinos). Avenida Theodomiro Porto da Fonseca, 1786 - São Leopoldo - RS - CEP 93020-080 E-mail: martin_petroll@yahoo.com.br 


\section{RESUMO}

A comunicação organizacional interna é uma vasta área de estudos discutida tanto no meio acadêmico quanto no organizacional por se tratar de um potencial fator responsável pela otimização dos diversos processos organizacionais. O desenvolvimento de novos produtos pode ser apontado como um exemplo desses processos. Acredita-se que, de forma direta ou indireta, a comunicação interna realizada entre os setores envolvidos com o desenvolvimento de novos produtos acaba por afetar os resultados da organização. Dessa forma, este trabalho busca analisar, por intermédio de pesquisa bibliográfica e estudo de caso, realizado em empresa de móveis nacional, os processos interfuncionais das áreas do marketing e produção no desenvolvimento de novos produtos e seus resultados para a empresa. Os resultados encontrados reafirmam a importância da comunicação interna e ressaltam que diferentes formas de comunicação trazem diferentes conseqüências à empresa.

\section{PALAVRAS - CHAVE}

Comunicação organizacional interna; Desenvolvimento de novos produtos; Interfuncionalidade; Processos comunicacionais; Diferentes formas de comunicação.

\section{ABSTRACT}

The inner communication is a wide area of studies discussed both in the academic and organizational environment since it refers to a potential factor responsible for the optimization of the various organizational processes. The development of new products can be pointed out as an example of these processes. Either directly or indirectly, the inner communication realized among the sectors involved in developing new products may impact the outcomes organization. Thus, this work aims at analyzing, through theoretical research and case studies carried out in a national furnishing company, the cross-functional processes of marketing and production in the development of new products and their results for the company. The found results ratify the importance of inner 
communication and emphasize that different way of communication bring different consequences for the company.

\section{KEYWORDS}

Inner organizational communication; Development of new products; Crossfunctionality; Communication processes; Different way of communication.

\section{INTROD U ÇÃ O}

A comunicação organizacional interna destaca-se, atualmente, como uma das práticas que exerce fundamental importância para o desenvolvimento das empresas e para a obtenção de melhores resultados por elas (HAUSMAN; MONTGOMERY; ROTH, 2002). Porém, dada a sua complexidade, a comunicação pode também se apresentar como sendo um dos grandes desafios a ser superado pelas empresas e um considerável gap teórico na Teoria da Administração e do Marketing (THAYER, I976; CALABRESE, I997).

Com base em ampla revisão teórica, Hausman, Montgomery e Roth (2002) afirmam que a comunicação, bem como a cooperação interfuncional, são antecedentes essenciais para o sucesso dos negócios e, também, exercem papel fundamental à otimização e rapidez do desenvolvimento de novos produtos (CALABRESE, I997). Quanto ao desempenho da organização, é importante enfatizar que a habilidade das áreas responsáveis pelo marketing e pela produção trabalharem juntas, em harmonia, pode melhorar os resultados do negócio e sua posição competitiva (HAUSMAN; MONTGOMERY; ROTH, 2002). Isso se deve ao fato de que um fator crítico de sucesso no mercado, hoje, consiste na habilidade de a empresa entender as necessidades do cliente e satisfazê-las (objetivo buscado pelo marketing) sem desconsiderar a sua realidade como organização, para a produção de bons produtos a um custo competitivo para empresa e mercado (MUKHOPADHYAY; GUPTA, I998).

Ao defenderem a integração entre marketing e produção, Hausman, Montgomery e Roth (2002) afirmam que o encurtamento do ciclo de vida dos produtos, as tecnologias avançadas em produtos e processos, a globalização, o consumismo e a rapidez nas mudanças tornam necessário o estreitamento dessas relações. No entanto, conflitos são gerados entre as áreas do marketing e da produção por causa, também, das diferenças de perspectivas ou objetivos entre elas (SHAPIRO, I977). Nesse sentido, Simantob e Lippi (2002) afirmam que o marketing restringe-se a dedicar esforços à satisfação do cliente e a produção em diminuir custos e aumentar a eficiência. O que falta, no entanto é a interação das áreas, a qual pode ser facilitada pela prática da comunicação. 
Observando, portanto, a relevância da comunicação interna para as empresas e as necessidades de maiores explorações nessa área, este trabalho tem como principal objetivo analisar, no âmbito teórico e também prático, por meio de estudo de caso, os processos comunicacionais internos de uma organização, pela verificação de pressupostos relativos à intenção do emissor no processo comunicacional, a perspectiva da comunicação e seu grau de formalidade. Podem ser considerados objetivos específicos deste estudo: a identificação dos elementos facilitadores e barreiras relacionadas ao desenvolvimento da comunicação no processo de desenvolvimento de novos produtos e, também, a observação das conseqüências do processo de comunicação organizacional interna nas perspectivas financeira gerencial e humano-relacional.

$\mathrm{O}$ recorte foi realizado nos processos realizados entre as áreas de marketing e produção no desenvolvimento de novos produtos. Dessa forma, os resultados do estudo possibilitam abordar como se desenvolvem, quais as barreiras, os facilitadores e as conseqüências geradas pelos diferentes processos comunicacionais que ocorrem entre marketing e produção no desenvolvimento de novos produtos, ressaltando a importância da comunicação perante os resultados da empresa.

A seguir, será apresentada a explanação teórica do estudo, a qual fará referências aos principais temas abordados e a descrição do método utilizado na pesquisa será feita logo em seguida. Os principais resultados obtidos encerram o artigo, que apresenta também implicações teóricas e gerenciais para os campos da administração e comunicação, além de propostas para futuros estudos.

\section{REFERENCIAL TEÓRICO}

Barnard (I979) refere-se à organização como sendo um sistema de atividades conscientemente coordenadas ou um sistema de forças de dois ou mais indivíduos. O autor enfatiza o aspecto cooperativo das organizações para que as capacidades individuais possam reunir-se na realização de tarefas complexas e ordenadas.

Em relação ao objeto de análise deste estudo, o processo de comunicação organizacional, aborda-se o conceito de Kreeps (I990) que o entende como um processo pelo qual os membros da organização obtêm as informações pertinentes sobre ela e as mudanças que nela ocorrem. No contexto de Goldhaber (I99I, p. I3),

A comunicação organizacional pode atuar como o processo de criação e troca de mensagens dentro de uma rede de trabalho de relações interdependentes para competir com as incertezas do ambiente. 
Ressalta-se que o presente trabalho delimita-se à análise dos processos de comunicação organizacional interna, os quais englobam todas aquelas mensagens enviadas ou recebidas dentro dos limites da organização. Seu desenvolvimento ocorre de diversas formas. Sendo assim, consideram-se reuniões, conferências, diálogos face a face, bem como os mais diversos instrumentos utilizados, tais como: intranet, murais, telefone, jornais internos, comunicados oficiais e formulários.

Quanto à importância e eficácia da comunicação na organização, Calabrese (I997) defende a comunicação e também a cooperação como ferramentas indispensáveis para responder imediatamente às constantes mudanças que acontecem no ambiente no qual estão inseridas as organizações e, segundo Reis (2002, p. I6): "Além de expressar a mudança, a comunicação é um elemento constitutivo da mudança”. Portanto, quando a comunicação organizacional é discutida, o que merece ênfase nessa discussão são os aspectos relativos à sua eficácia: "A comunicação eficaz é considerada uma prioridade para as organizações” (ANDREWS; HERSHEL, I996, p. 39). Essa comunicação consiste na colaboração, interação e comprometimento dos funcionários pela construção de significado na mensagem (BARKER; CAMARATA, I998) e não apenas na simples troca de informações.

\subsection{A INFORMAÇÃO E A COMUNICAÇÃO}

Thayer (1976) considera importante, primeiramente, diferenciar dados de informação, como prática fundamental para se compreender a comunicação. Para o autor, o mundo que nos cerca é formado por uma sucessão infinita de "acontecimentos-dados" em movimento. A partir do momento em que nossos sentidos tomam posse desses dados, impondo estrutura, expressão, significação ou utilidade a eles, esse "produto" torna-se informação, ou seja, torna-se algo considerado significativo. Portanto, informações são dados impregnados de significado. À comunicação, por sua vez, está subjacente o processo de transformar os dados, até então brutos, em informações processáveis ou consumíveis, por meio de trocas mútuas (THAYER, I976).

No entanto, Thayer (I976) enfatiza a dificuldade em se tratar a comunicação organizacional e, principalmente, a eficácia dessa comunicação. Segundo esse autor, a dificuldade é decorrente da falta de distinção que ocorre entre a eficácia do desempenho comunicativo e a eficácia do encontro comunicativo: não é estabelecida a exata diferença entre a simples compreensão de uma mensagem e o comportamento subseqüente do receptor, com relação às intenções do emissor. Ou seja, é possível que o receptor entenda claramente a mensagem enviada - eficácia do encontro comunicativo - o que não significa, no entanto, que será feito o que era esperado pelo emissor. 
Por sua vez, as teorias da comunicação apresentam uma série de escolas, teóricos e modelos que buscam clarificar e conceitualizar essa área de estudos. Neste trabalho, são apresentados dois modelos clássicos dos processos de comunicação: o modelo baseado na teoria da informação (SHANNON; WEAVER, I962) e o Modelo de Comunicação Transacional (SCHRAMM, I97I). Ambos foram escolhidos por possibilitarem a este estudo a observação dos processos comunicacionais internos a partir de dois ângulos: o que baseia a intenção do emissor na simples troca de informação e aquele que visa à realização da comunicação como um processo de trocas e construção de mensagens. A partir destes modelos, portanto, pode ser feita uma distinção entre as diferentes formas de comunicação desenvolvidas na organização, a fim de facilitar sua análise na fase empírica deste estudo.

\subsubsection{A TEORIA DA INFORMAÇÃO}

A teoria da informação, ou teoria matemática da comunicação (Figura I), desenvolvida por Shannon e Weaver (I96I) na década de I940, está fundamentada em trabalhos realizados na engenharia das telecomunicações. Segundo Wolf (2002), essa teoria apresenta a otimização da transmissão de mensagens, e uma de suas grandes contribuições é permitir individualizar fatores de perturbação da transmissão de informações, os ruídos. É destacada a presença de um importante elemento nesse modelo: o código. Ele é importante para que o destinatário possa compreender o sinal (WOLF, 2002).

\section{FIGURA I}

\section{MODELO COMUNICATIVO DA TEORIA DA INFORMACAOO}

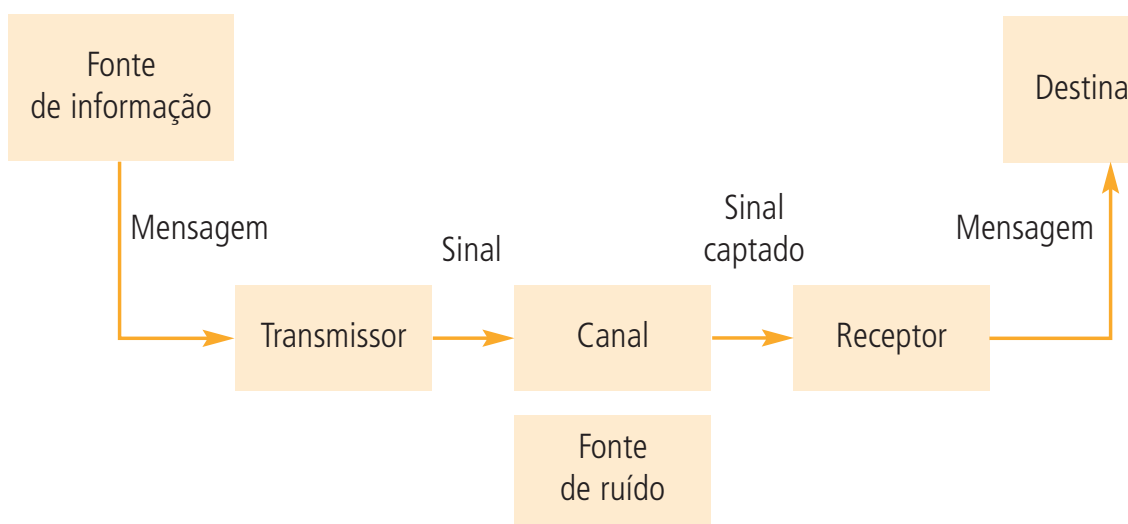

Fonte: Adaptada de Shannon e Weaver (1962). 
Em nível organizacional, quando as organizações planejam sua comunicação na crença da passividade de seus públicos, perspectiva baseada no modelo de comunicação informacional, elas podem, segundo Baldissera (2000), sofrer como conseqüências: a) falta de conhecimento das formas de comunicação e do público-alvo; b) circulação de informações desencontradas; c) uso de linguagem não acessível ao público-alvo; d) codificações inapropriadas, as quais permitem interpretações indesejadas; e) inexistência de fio condutor para a comunicação oficial; f) mensagens complexas; e g) falta de avaliação e retroalimentação do processo comunicacional. Kunsch (2003) apresenta uma visão semelhante à do autor anteriormente mencionado. Ela propõe que as organizações que se comportam como fontes emissoras de informação, apenas, sem que haja preocupações com as conseqüências desse ato de "informar", não devem ter a ilusão de que todos os seus processos comunicativos causam os efeitos positivos desejados ou são respondidos e aceitos da forma como foram intencionados.

\subsubsection{A TEORIA DA COMUNICAÇÃO TRANSACIONAL}

No que se refere aos processos comunicacionais, o Modelo Transacional de Comunicação (Figura 2) é considerado o mais contemporâneo, enfatizando a comunicação two-way e os processos recíprocos de trocas de mensagens mútuas (ANDREWS; HERSHEL, I996). Ele é a herança da revisão feita por Schramm (I97I) do modelo informacional de comunicação que traz uma contribuição significativa aos modelos funcionais, inserindo nos mesmos elementos relacionados à decodificação da mensagem e modificação desta pelo emissor. Também traz o conceito de feedback ao processo de comunicação, que reorienta seu caráter unilateral para a perspectiva de mão dupla (SCHRAMM, I97I).

Axley (I984), ao comparar o Modelo Transacional com o modelo de visão linear de comunicação, ressalta que, neste último, o significado de uma mensagem pertence ao emissor, e o desafio consiste em utilizar efetivamente um canal e, então, transmitir a mensagem claramente para um receptor ou grupo. Já o Modelo Transacional está ajustado ao receptor e para a construção de um significado da mensagem em sua mente. Barker e Camarata (1998) defendem que esse processo de troca de mensagens e construção de significados é o ideal para ser desenvolvido no ambiente organizacional. Segundo esses autores, somente dessa forma a disseminação de conhecimento e enriquecimento das relações poderá gerar o aprendizado organizacional necessário às constantes adaptações da empresa às mudanças do ambiente e à busca da inovação. 


\section{FIGURA 2}

\section{MODELO TRANSACIONAL DE COMUNICACAO}

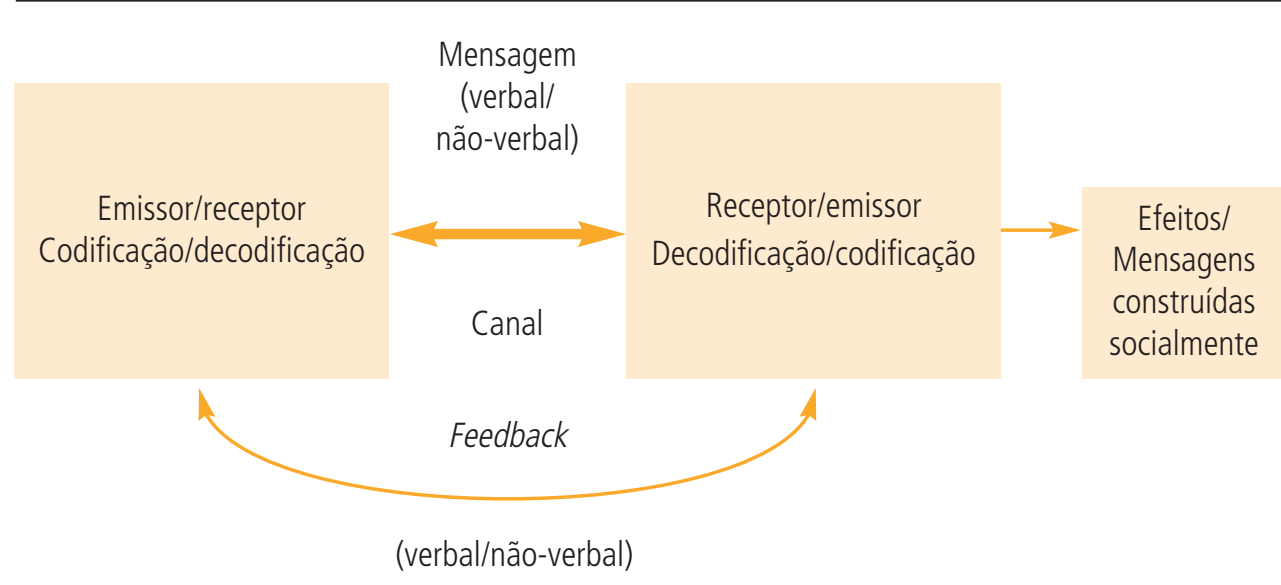

Fonte: Adaptada de Andrews e Hershel (I996).

\subsection{CARACTERÍSTICAS DA COMUNICAÇÃO}

Para que os processos comunicativos possam ser analisados de forma objetiva e substancial, além dos modelos nos quais pode estar apoiada a intenção do emissor, citados anteriormente, outras características devem ser investigadas. Isso se deve ao fato de se estar diante de um fenômeno bastante complexo, no qual, segundo Kunsch (2003), é preciso levar-se em conta os aspectos relacionais, os contextos, os condicionamentos internos e externos, bem como a complexidade que permeia todo o processo comunicativo. As abordagens que se seguem, portanto, descrevem as diversas formas de análise da comunicação que serão tratadas neste estudo.

A primeira delas diz respeito ao grau de formalidade da comunicação. A comunicação na organização pode apresentar-se sob caráter formal ou informal. O'Hair, Friedrich e Dixon (2002) descrevem que a comunicação formal inclui o estabelecimento de políticas apresentadas pela direção, as notícias de mudanças nas operações e processos e as instruções vindas dos superiores. Já a comunicação informal não é baseada nas normas organizacionais, necessariamente, podendo mesmo assim ser ainda mais importante do que as impostas pelo sistema organizacional (O'HAIR; FRIEDRICH; DIXON, 2002). Para que haja harmonia interna é necessário, portanto, um equilíbrio entre ambas no cotidiano da empresa (ROBBINS, 2000).

A segunda abordagem apresenta a perspectiva da comunicação. Nesta, a comunicação organizacional pode ser observada sob uma perspectiva funcionalis- 
ta, em que é compreendida por seu caráter produtivo e integrador, ou sob uma perspectiva interpretativa, na qual é considerado o seu papel organizante de mediação das construções sociais.

Kunsch (2003) defende, nessa abordagem, a necessidade de ultrapassar a simples visão mecanicista da comunicação, representada na visão funcionalista, para outra mais interpretativa e crítica. Essa seria a visão que traria à empresa os benefícios gerados pela comunicação por considerar a complexidade e influência do ambiente social no processo comunicacional e suas implicações.

A terceira característica abordada refere-se às direções da comunicação, normalmente apresentadas como sendo ascendente, descendente e horizontal (ANDREWS; HERSHEL, I996). Este trabalho, porém, adota, diante de suas análises, a idéia de que toda a comunicação, independentemente da sua direção linear caracterizada, pode ser considerada circular. Isso decorre do fato de se considerar que, mesmo pressupondo-se que haja uma linearidade do processo comunicativo, o feedback gerado pela comunicação acarretará numa circularidade da informação, e esse fluxo circular "abarca todos os níveis sem se ajustar às direções tradicionais e seu conteúdo pode ser tanto mais amplo quanto maior for a aproximação das relações interpessoais" (GORTARI; GUTIÉRREZ, I990 apud KUNSCH, 2003, p. I36).

\section{2 - 3 COMUNICAÇÃO E INTERFUNCIONALIDADE ENTRE MARKETING E PRODUÇÃO}

Nas últimas décadas, ocorreram mudanças de orientação na organização. Tradicionalmente voltada à produção, ela estaria focando sua orientação ao mercado (PARENTE, I998). Shapiro (I977) reconhece, no entanto, a importância do relacionamento entre ambos, marketing (mercado) e produção, e ressalta os perigos para a empresa que baseia sua política de ação em apenas uma das duas áreas, aconselhando a coexistência de ambas as orientações, voltadas à produção e ao mercado, na empresa.

O relacionamento interfuncional é considerado uma interação entre duas funções do negócio e pode ocorrer em diferentes níveis (PARENTE, I998). A integração interfuncional efetiva é considerada uma atividade que a empresa deve desenvolver para competir no desenvolvimento de capacitações, colaborando com o eficiente desenvolvimento de produtos (SMITH; REINERTSEN, I997).

No que se refere ao desenvolvimento de novos produtos, Smith e Reinertsen (I997) apontam que a interfuncionalidade é importante para troca de conhecimento. É fundamental que todos os especialistas envolvidos no processo compartilhem informações para encontrar uma solução satisfatória. O marketing é importante nesse processo, uma vez que todos devem compreender quem 
é o cliente e quais necessidades devem ser satisfeitas e a produção por poder repassar informações mais práticas sobre a realidade e recursos da empresa (SMITH; REINERTSEN, I997).

A comunicação, por sua vez, é uma das questões-chave nas interações e na busca por uma maior cooperação entre as funções. Ela possui um efeito moderador, que diminui a influência das barreiras geradoras de conflitos na cooperação entre os diferentes departamentos (MALTZ, I997). Ruekert e Walker (I987) destacam a importância da comunicação entre pessoas de diferentes áreas na interação interfuncional e constatam em sua pesquisa que os conflitos entre as funções estão fortemente relacionados com a dificuldade de comunicação entre elas.

\section{MÉTODO}

O método utilizado na etapa empírica desta investigação é o estudo de caso único, justificado pelas condições complexas que se apresentam ao se estudar a comunicação nas organizações (CHANLAT, I99I), a qual requer profundidade no estudo e abertura de informações detalhadas da empresa e dos sujeitos envolvidos (THAYER, I976). O método de estudo de caso é uma estratégia de pesquisa que busca examinar um fenômeno contemporâneo dentro do seu contexto real. Para Yin (200I), as questões "como" e "por que" podem capturar o que realmente se está interessado em responder, e busca chamar o pesquisador para as evidências relevantes. Essa pergunta busca respostas a um conjunto de eventos contemporâneos que representam a realidade na sua forma atual e presente, em que o investigador tem pouco ou nenhum controle, e os fenômenos e o contexto não são claramente definidos. Nesse sentido, o pesquisador não tem a necessidade de controlar os eventos de comportamento do objeto de estudo, mas sim de compreendê-los.

Além disso, os dados qualitativos são coletados para se conhecer melhor os aspectos que não podem ser coletados e medidos diretamente (AAKER; KUMAR; DAY, 200I). A subjetividade do tema proposto neste estudo, a comunicação e a importância de todo o processo da pesquisa, não somente seus resultados, encaminham aos métodos qualitativos de análise (GODOY, I995).

O estudo de caso foi realizado em empresa de móveis, localizada no Estado do Rio Grande do Sul, no Município de Bento Gonçalves, focando as suas áreas de marketing e produção. A empresa é considerada pela ABIMÓVEL - Associação Brasileira das Indústrias do Mobiliário (2004) - uma das maiores fabricantes de móveis do Estado. A escolha do setor moveleiro é justificada, uma vez que além de preço, o mercado de móveis caracteriza-se pela constante inovação no design de seus produtos, que precisam estar constantemente sendo adequados às 
tendências do mercado, valores culturais, desejos do consumidor e qualidade (DE TONI, I998). Além disso, o setor de móveis vem se destacando e, atualmente, apresenta um faturamento significativo junto à economia nacional correspondente a R\$ Io,3 bilhões, segundo dados da ABIMÓVEL (2004).

A execução da coleta e análise de dados foi precedida e guiada pelo protocolo que, segundo Yin (200I), é uma das táticas fundamentais para se manter a confiabilidade da pesquisa e deve ser usado a fim de orientar o pesquisador, contendo, além do instrumento de pesquisa, também os seus procedimentos e regras de utilização. Esses procedimentos são apresentados de forma esquemática na Figura 3.

\section{FIGURA 3}

\section{ESQUEMA DOS PROCEDIMENTOS METODOLOGICOS}

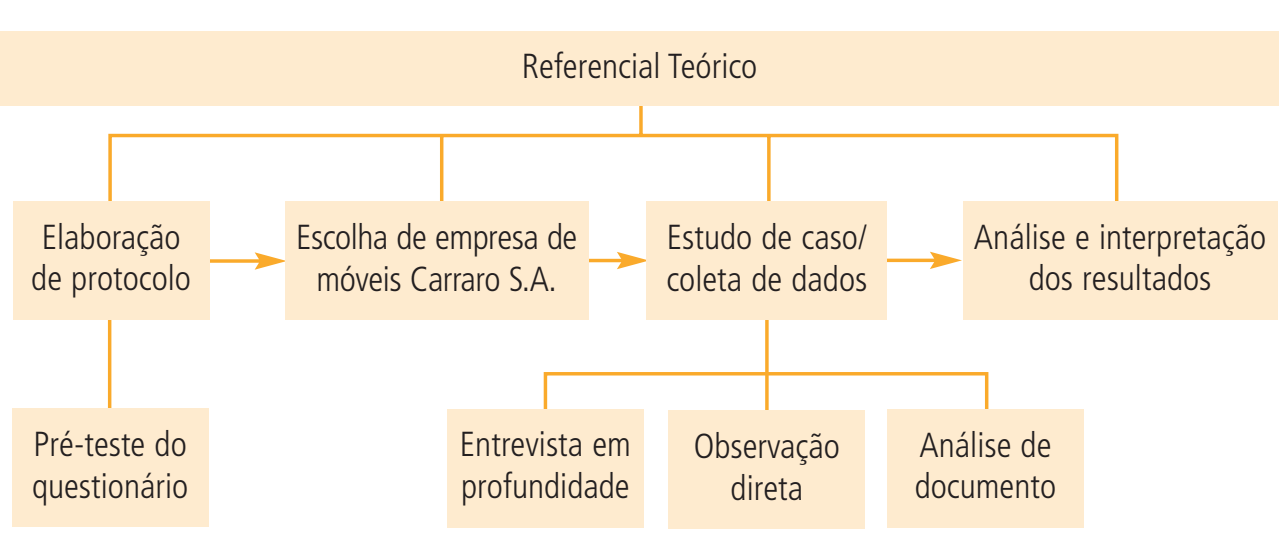

Fonte: Desenvolvida pelos autores.

No Protocolo foram definidos, portanto, os instrumentos para coleta de dados: as entrevistas em profundidade, a análise de documentos e observação direta. As entrevistas semi-estruturadas em profundidade seguiram um roteiro elaborado a partir de teorias referenciadas e dos objetivos da pesquisa. Além disso, o formato semi-estruturado do roteiro também consentiu que novas abordagens fossem feitas ao longo da realização da entrevista, conforme novos apontamentos feitos pelos entrevistados (TRIVIÑOS, I987). Considerando a natureza exploratória do estudo e das técnicas de coleta de dados, a análise dos dados seguiu, neste trabalho, o método de análise de conteúdo do tipo temática, inspirada nas indicações de Bardin (I977). Essa análise possibilita a descrição do conteúdo apresentado pelos entrevistados e dados coletados para, posteriormente, interpretá-los. Foram entrevistados, além do diretor-presidente da empresa, os responsáveis pelas 
áreas: vendas/marketing, designer de produtos, produção, comunicação e qualidade e time de idéias. Essas entrevistas foram realizadas durante os meses de outubro e novembro de 2004 .

Tanto nas entrevistas em profundidade quanto nas observações diretas, procurou-se colher os seguintes dados: histórico e situação atual da comunicação na empresa, instrumentos de comunicação utilizados entre os diversos atores e diferentes etapas do desenvolvimento de novos produtos, principais barreiras e facilitadores da comunicação, conseqüências da comunicação para a empresa diante de seus diferentes modelos de desenvolvimento: informacional ou transacional, além das suas características: grau de formalidade, perspectiva e direção.

Os documentos analisados foram definidos como aqueles fornecidos pela empresa (tais como relatórios, informativos internos, boletins etc.) e também documentação disponível em meios eletrônicos ou mídia em geral. Quanto à observação direta, restringe-se a atividades informais de coletas de dados (YIN, 200I) no ambiente interno da empresa durante a realização das entrevistas, de aspectos considerados relevantes pelo pesquisador, perante o problema (MALHOTRA, 200I). A triangulação das fontes de evidências, sugerida por Yin (200I), foi a técnica adotada para que fossem minimizadas as possíveis tendenciosidades no estudo e para aumentar a qualidade da pesquisa.

\section{RESULTADOS}

Por intermédio da análise dos resultados obtidos perante o estudo de caso realizado em representativa empresa moveleira do pólo gaúcho de Bento Gonçalves, nas áreas de marketing e produção, este estudo permite definir as principais barreiras, facilitadores e consequiências da comunicação eficaz desenvolvida junto à organização. Além disso, pressupostos foram estabelecidos diante da triangulação dos dados teóricos e empíricos obtidos.

\section{1 FACILITADORES E BARREIRAS DA COMUNICAÇÃO}

Ao longo dos últimos dois anos, a empresa analisada sofreu sérias modificações na sua estrutura interna e no seu quadro de funcionários (especialmente na área de marketing), o que acabou acarretando uma mudança positiva perante os seus processos comunicacionais, os quais hoje podem ser considerados eficazes. Dessa forma, as barreiras e facilitadores apontados neste estudo foram traçados por uma descrição comparativa de dois momentos distintos: um pré e outro pós-mudanças. 
Apesar de todos os apontamentos citados nas entrevistas serem de grande relevância, enfatizam-se como principais facilitadores ou barreiras da comunicação aqueles relacionados ao caráter humano-relacional da empresa. Ou seja, a capacidade em aceitar críticas e relacionar-se com os colegas apresentou-se como fundamental ao desenvolvimento de uma comunicação eficaz na empresa: “[...] as pessoas precisam conversar e ser ouvidas para a empresa funcionar", afirma um dos entrevistados.

Quanto aos facilitadores, torna-se importante ressaltar que, em todas as entrevistas realizadas, sempre foi mencionada a característica de "líder nato" no diretor da empresa. Tal característica, segundo os entrevistados, permite que a empresa seja aberta, flexível, com uma comunicação fluente e relacionamentos que permitem um ambiente próspero e comprometido aos objetivos da empresa.

Os meios formais de trocas de informação, como as reuniões promovidas semanalmente, por exemplo, foram citados pela maioria dos entrevistados como facilitadores da comunicação. O layout interno da empresa foi citado por facilitar o estreitamento das relações dadas as poucas barreiras físicas do ambiente. Também está presente na empresa uma postura de deslocamento da tomada de decisão para mais perto das fontes de informação. E, segundo Galbraith e Lawler (I995), esta pode ser considerada uma postura que facilita a comunicação interna e traz resultados positivos à empresa.

Quanto às barreiras observadas junto à comunicação da empresa, da mesma forma que os facilitadores, observa-se que elas estão intimamente relacionadas aos fatores humanos-relacionais. A dificuldade de relacionamento e o descaso ou intransigência de colegas ou superiores são abordados como fatores que podem gerar sérias barreiras diante de uma comunicação eficaz. Por exemplo, a falta de atenção ou respostas junto aos comentários e propostas dos funcionários acaba por desperdiçar possíveis contribuições ao desenvolvimento de novos produtos ou gera feedbacks negativos junto a resultados fracassados de certos produtos. "Eu disse, mas ninguém me ouviu", é um exemplo de frase citado por um dos entrevistados como sendo resultante da falta de atenção dos superiores. Esse tipo de procedimento acaba por gerar descomprometimento ou desmotivação dos funcionários junto à empresa.

Outra barreira apontada, especialmente no período pré-mudanças, diz respeito à retenção da informação como forma de o superior ou funcionário manter-se indispensável à empresa. Na teoria, Thayer (1976) enfatiza a manipulação da informação como possibilidade de oportunizar vantagens pessoais que podem impedir o fluxo de informações, acarretando resultados negativos à empresa. $\mathrm{O}$ Quadro I apresenta, de forma objetiva, facilitadores e barreiras identificados no estudo de caso: 


\section{QUADRO I}

FACILITADORES E BARREIRAS COMUNICACIONAIS

FACILITADORES DA COMUNICAÇÃO

- Capacidade pessoal de se relacionar, aceitar críticas e sugestões.

- Posicionamento da direção.

- Encontros promovidos pelas reuniões.

- Layout da empresa (divisões internas e disposição dos móveis) que intensifique interações e que permita a prática da comunicação informal.

- Estrutura organizacional que incentive o trabalho em equipe.

- Tecnologia dos e-mails e intranet.

- Congruência de objetivos entre funcionários e empresa.

- Delegação de poder às fontes de informação diante da tomada de decisão.
BARREIRAS DA COMUNICAÇÃO

- Dificuldades nos relacionamentos.

- Incapacidade em aceitar críticas e sugestões.

- Intransigência ou descaso dos superiores.

- A falta de respostas aos funcionários e colegas perante tentativa destes de trazerem contribuiç̧ões gera desmotivação pessoal no trabalho e descomprometimento.

- Divergências nos objetivos das áreas.

- Exercício e manifestação de poder pela retenção da informação.

- Insegurança profissional (que acarreta a necessidade de reter informações para ser "indispensável").

- Falta de capacidade de repassar informação absorvida ou conhecimento aos colegas.

- Intensa competitividade interna.

Fonte: Estruturada pelos autores, a partir de informações obtidas junto às fontes de evidência.

\subsection{COMUNICAÇÃO E CONSEQÜÊNCIAS PARA A EMPRESA}

Um fator que facilitou a identificação das diferentes formas de a empresa se comunicar foram os momentos distintos passados por ela, já citados anteriormente. A partir das mudanças observadas, torna-se relativamente fácil traçar um quadro comparativo das conseqüências negativas da comunicação que existia, e as conseqüências positivas que hoje a empresa obtém, por meio de uma política interna em que os fluxos de comunicação são realmente efetivos e permanentes. Ou seja, no período antecedente a tais mudanças, os funcionários narram que a forma de se relacionar e trocar informações era bastante deficitária. Hoje, a comunicação interna pode ser considerada eficaz.

Como principais conseqüências de ordem humano-relacional acarretadas por essas falhas na comunicação, as entrevistas apontam principalmente o aumento de conflitos interpessoais gerados pela falta de diálogo e o constante clima de insegurança e arrogância na empresa, além da insatisfação e desmotivação pessoal para o trabalho, dada a falta de atenção dispensada por parte do superior. A frase mais ouvida nos feedbacks negativos acarretados e que melhor retrata esse momento, segundo os entrevistados, era: "Eu falei, eu sabia... mas ninguém me ouviu”. O Quadro 2 resume as principais conseqüências, as quais podem ser relacionadas às falhas na comunicação que ocorriam na empresa. 
QUADRO 2

CONSEQUENCIAS RELACIONADAS AS FALHAS NA COMUNICACÃO NA EMPRESA

\section{CONSEQÜÊNCIAS FINANCEIRAS E GERENCIAIS}

- Prejuízos no desenvolvimento de novos produtos.

- Prejuízos operacionais pelo desentendimento de mensagens.

- Diminuição de base argumentativa para as ações de vendas/marketing junto ao mercado.

- Maior suscetibilidade à inadequação de produtos no mercado.

\section{CONSEQÜÊNCIAS HUMANO-RELACIONAIS}

- Aumento de conflitos interpessoais.

- Insatisfação e desmotivação pessoal no trabalho.

- Descomprometimento e feedbacks negativos após o insucesso do produto no mercado (ex.: "eu falei, mas ninguém me ouviu").

Fonte: Estruturada pelos autores, a partir de informações obtidas junto às fontes de evidência.

Após as mudanças, porém, uma realidade diferente no ambiente interno é descrita pelos funcionários. Nela, podem-se perceber alterações significativas na comunicação, relacionamentos internos, e até externos, e em suas conseqüências. O Quadro 3 divide as conseqüências geradas, direta ou indiretamente, pela melhor comunicação interna desenvolvida na empresa no período atual:

\section{QUADRO 3}

\section{CONSEQUENCIAS RELACIONADAS A PRATICA} DA COMUNICACÃO NO PERIIODO PÓS-MUDANCAS

\section{CONSEQÜÊNCIAS FINANCEIRAS E GERENCIAIS}

- Maior rapidez no desenvolvimento de novos produtos.

- Maior adequação dos produtos no mercado.

- Argumentos de marketing e vendas melhor fundamentados.

- Produtos ganham um maior diferencial através da qualidade que sempre é buscada e discutida entre os funcionários.

- Ampliação de idéias de produtos e oportunidades no mercado.

- Otimização dos resultados e diminuição de custos no desenvolvimento de novos produtos.

- Maior interação das áreas de marketing e produção.

- Redução da necessidade de refazer as tarefas durante o desenvolvimento de novos produtos.

- Aumento do faturamento da empresa (pode ser considerada indireta).

\section{CONSEQÜÊNCIAS HUMANO-RELACIONAIS}

- Maior comprometimento dos funcionários.

- Aumento da empatia entre funcionários e entrosamento das equipes.

- Ambiente trabalho mais favorável ao desenvolvimento de relações interpessoais.

- Maior liberdade de expressão e motivação pessoal.

- Maior aproveitamento das capacidades pessoais.

Fonte: Estruturada pelos autores, a partir de informações obtidas junto às fontes de evidência. 


\subsection{PRESSUPOSTOS}

O referencial teórico buscou consolidar e estruturar as características da comunicação e os conceitos mais relevantes apontados neste estudo, os quais constituíram o marco referencial utilizado na análise do estudo de caso. Com base nele, e por meio das informações obtidas pelo estudo de caso, são relacionados, nos tópicos abaixo, pressupostos com o objetivo de ampliar e fundamentar organizadamente algumas questões debatidas.

\subsubsection{MODELO COMUNICACIONAL NO QUAL ESTÁ BASEADA A INTENÇÃO DO EMISSOR}

Pressuposto I: Quando o emissor estiver baseado no Modelo Informacional, ou seja, ele somente estiver preocupado em transmitir a informação, os resultados positivos alcançados podem ser menores do que quando o emissor intencionar o fechamento do ciclo comunicacional pelo feedback, o que é possível na comunicação baseada no Modelo Transacional.

Diferentes realidades foram observadas em dois períodos distintos na empresa. No primeiro, quando a comunicação tinha como fim a manutenção do poder, por meio da retenção da informação, as conseqüências de tal ação mostraram não ser positivas para a empresa e para o desenvolvimento de novos produtos. No segundo momento, a intenção dos emissores passou a ser mais freqüentemente baseada na comunicação transacional, e os principais benefícios foram: maior participação e comprometimento dos funcionários, rapidez no desenvolvimento de novos produtos, maior número (cerca de 30\% a mais) e maior adequação de recursos no desenvolvimento de novos produtos.

\section{3. 2 PERSPECTIVA OU VISÃO DA COMUNICAÇÃO}

Pressuposto 2: A comunicação, baseada na perspectiva interpretativista, traz melhores resultados ao desenvolvimento de novos produtos e à empresa.

A visão funcionalista predomina diante da postura da empresa estudada. Ou seja, a comunicação é compreendida por seu caráter produtivo e integrador (ANDREWS; HERSHEL, I996). Porém, apesar de poucos, os encontros comunicativos que possuem uma visão interpretativista na empresa parecem ser os responsáveis pelo compartilhamento de visões de mundo e difusores dos objetivos pessoais e organizacionais. E é essa difusão dos objetivos que pode maximizar os esforços e gerar comprometimento. É o caso das reuniões semanais e o Programa de Idéias desenvolvido pela empresa. 


\subsubsection{GRAU DE FORMALIDADE DA COMUNICAÇÃO}

Pressuposto 3: O equilíbrio entre comunicação formal e informal é o que trará melhores resultados à empresa. Os meios formais de comunicação são fundamentais, pois permitem uma oficialização, segurança e clareza muitas vezes requisitadas pelos "acordos" informais estabelecidos entre as áreas.

A Figura 4 representa, de forma sistemática, os três pressupostos apresentados neste trabalho. Ela apresenta a relação linear entre o modelo teórico em que está baseado o processo da comunicação e o seu grau de influência na empresa, no que tange à maior ou menor interfuncionalidade entre marketing e produção e conseqüências positivas no desenvolvimento de novos produtos.

\section{FIGURA 4}

\section{REPRESENTAÇAO DAS CARACTERISTICAS E INFLUÊNCIA DA COMUNICAÇÃO}

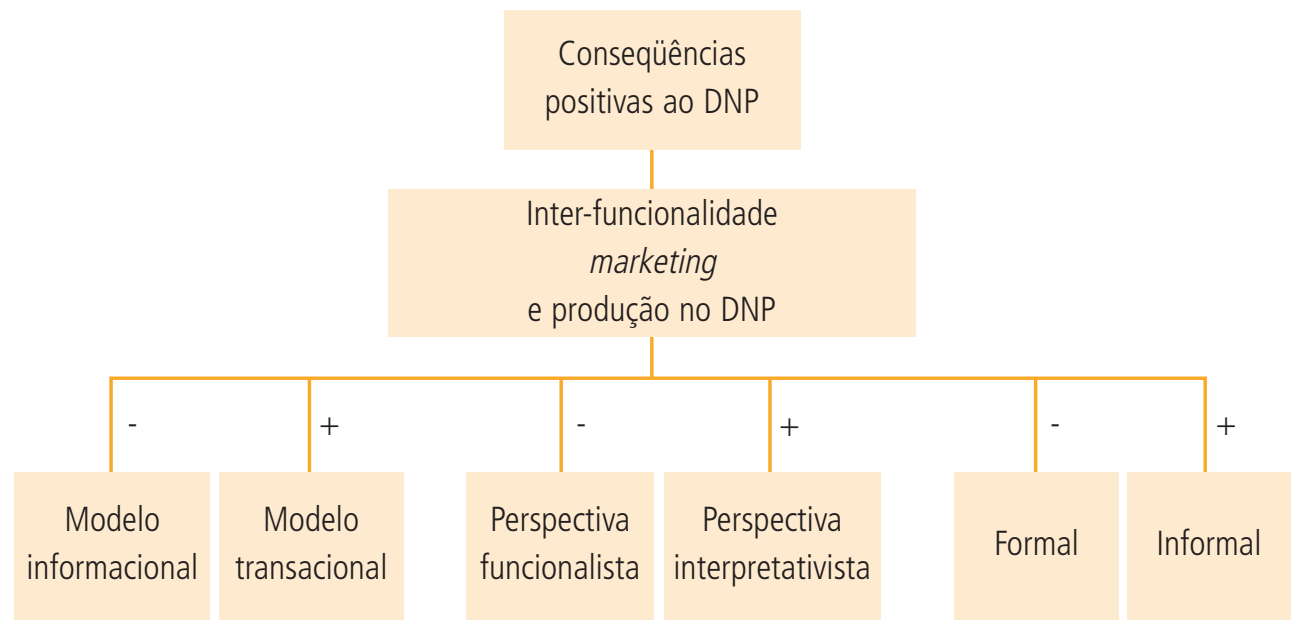

Fonte: Desenvolvida pelos autores.

\section{DISCUSSÃO DOS RESULTAdOS E CONCLUSÕES}

De acordo com informações colhidas e pressupostos descritos sobre a comunicação organizacional interna e análises desenvolvidas sobre suas conseqüências na empresa, observa-se que a interfuncionalidade do marketing e produção e as diferentes características apresentadas pelos processos comunicacionais ge- 
ram diferentes conseqüências aos resultados da empresa estudada. Portanto, torna-se importante ressaltar os cuidados que devem ser tomados perante o desenvolvimento da sua comunicação interna.

Dessa forma, corroborando com os estudos de Baldissera (2000) e Kunsch (2003), a comunicação deve ser refletida no ambiente organizacional para que sejam evitadas as falsas crenças de que todos os atos comunicativos causam os efeitos positivos desejados ou que todos são automaticamente respondidos e aceitos da forma que foram intencionados pela empresa.

Uma série de questões foi identificada na literatura pesquisada e confirmada pela pesquisa empírica diante do alcance de melhores resultados pela empresa. É o caso da relevância do desenvolvimento de uma comunicação baseada no Modelo Transacional da comunicação (BARKER; CAMARATA, I998; AXLEY, I984), na perspectiva interpretativista e do equilíbrio necessário entre a comunicação informal e formal na empresa (KUNSCH, 2003). Porém, é no que se refere às conseqüências da comunicação para a empresa que se quer dar ênfase aqui e, também, às relações entre Administração e Comunicação evidenciadas no campo teórico.

Por intermédio da pesquisa bibliográfica, pôde-se perceber certas restrições, tanto na área da comunicação quanto da administração, em se tratando da aproximação dos estudos entre ambas. Apontaram-se no estudo as dificuldades em se trabalhar a comunicação na empresa ante a subjetividade da última em relação à primeira. No entanto, em vista dos resultados obtidos, percebe-se que deve haver maior preocupação, por parte dos pesquisadores, em investigar esse vasto campo, ainda complexo, porém de fundamental importância: o da comunicação organizacional interna.

Quanto às consequiências da comunicação na empresa, verifica-se, por exemplo, que vários benefícios trazidos pela comunicação ainda não ganharam a ênfase merecida nos estudos de campo. É o caso da melhora da argumentação de marketing perante os clientes e concorrentes quando ele estiver interado com os processos produtivos da empresa. Os outros benefícios são: a) maior aproveitamento das capacidades pessoais e organizacionais pela comunicação; b) relação entre comunicação eficaz e aumento do faturamento na empresa; e, por fim, c) a função da comunicação diante da manutenção do poder na empresa (uma vez que foi identificado no estudo que a comunicação pode acabar exercendo maior influência sobre questões internas do que a própria hierarquia organizacional).

Apesar de terem sido tomados os cuidados apontados por Yin (200I) quanto à validade e confiabilidade deste estudo, por se tratar de estudo de caso único, as implicações e apontamentos aqui apresentados não são passíveis de generalização. No entanto, os pressupostos e implicações descritos, que têm a intenção de aproximar as áreas de comunicação e administração, podem servir de base a outros estudos e pesquisas realizadas nessas áreas. 
Para trabalhos futuros, propõem-se estudos aprofundados das relações entre comunicação e poder, pois se constatou que a comunicação pode ganhar mais relevância, em algumas situações, do que a própria hierarquia da empresa. Ressaltam-se, também, as constatações observadas sobre a perspectiva interpretativa da comunicação na empresa e a riqueza que um estudo mais profundo sobre o tema pode trazer ao estudo da comunicação organizacional. E, por fim, propõem-se que pesquisas quantitativas se apóiem nos pressupostos deste estudo, para que possam ser generalizadas posteriormente.

\section{REFERÊNCIAS}

ABIMÓVEL - Associação Brasileira das Indústrias do Mobiliário. Panorama do Setor Moveleiro no Brasil. São Paulo, ago. 2004. Disponível em: <http://www.abimovel.com>. Acesso em: Io set. 2004.

AAKER, David; KUMAR, V.; DAY, George. Pesquisa de marketing. São Paulo: Atlas, 200 I. ANDREWS, Patricia; HERSHEL, Richard. Organizational communication. Empowerment in a technological society. Boston: Houghton Mifflin Company, I996.

AXLEY, Stephen. Managerial and organizational communication in terms of the conduit metaphor. The Academy of Management Review, Briancliff manor, v. 9, n. 3, p. 428437, jul. I984.

BALDISSERA, Rudimar. Comunicação organizacional: o treinamento como rito de passagem. São Leopoldo: Unisinos, 2000.

BARDIN, Laurence. Análise de conteúdo. Lisboa: Edições 70, I977.

BARKER, Rondolph; CAMARATA, Martin. The role of communication in creating and maintaining a learning organization: preconditions, indicators, and disciplines. The Journal of Business Communication, Urbana, v. 35, n. 4, p. 443-447, 1998.

BARNARD, Chester. As funções do executivo. São Paulo: Atlas, I979.

CALABRESE, Giuseppe. Communication and co-operation in product development: a case study of a European car producer. $R$ \& $D$ Management, Oxford, v. 27, n. 3, p. 239-252, 1997. CHANLAT, Jean-François. O indivíduo nas organizações: dimensões esquecidas. São Paulo: Atlas, I991.

DE TONI, Deonir. O processo de desenvolvimento de novos produtos: um estudo de caso na indústria plástica do segmento acessórios para móveis. 1998. Dissertação (Mestrado em Administração) - Universidade Federal do Rio Grande do Sul, Porto Alegre, I998.

GALBRAITH, Jay; LAWLER, Edward. Organizando para competir no futuro. São Paulo: Makron Books, I995.

GOLDHABER, Gerald. Comunicación organizacional. México: Editorial Diana, I99I. GODOY, Arilda Schmidt. Introdução à pesquisa qualitativa e suas possibilidades. RAE - Revista de Administração de Empresas, São Paulo, v. 35, n. 2, p. 57-63, I995.

HAUSMAN, Warren; MONTGOMERY, David; ROTH, Aleda. Why should marketing and manufacturing work together? Some exploratory empirical results. Journal of Operation Management, Columbia, v. 20, n. 3, p. 24I-247, 2002. 
KREEPS, Gary. Organizational communication: theory and practice. 2. ed. Nova York: Longman, I990.

KUNSCH, Margarida. Planejamento de relações públicas na comunicação integrada. São Paulo: Summus, 2003.

MALHOTRA, N. Pesquisa de marketing: uma orientação aplicada. Porto Alegre: Bookman, $200 I$.

MALTZ, Elliot. An enhaced framework for improving cooperation beetwen marketing and other functions: the differential role of integrating mechanisms. Journal of MarketFocused Management, Boston, v. 2, n. I, p. II2-I35, I997.

MUKHOPADHYAY, Samar; GUPTA, Anil. Interfaces for resolving marketing, manufacturing and design conflits. A conceptual framework. European Journal of Marketing, Bradford, v. 32, n. I/2, I998.

O'HAIR, Dan; FRIEDRICH, Gustav; DIXON, Linda. Strategic communication in business and the professions. 4. ed. Boston: Houchton Mifflin Company, 2002.

PARENTE, Diane. Across the manufacturing-marketing interface classification of significant research. International Journal of Operations \& Product Management, Bradford, v. I8, n. I2, p. I205, I998.

REIS, Maria do Carmo. Comunicação e mudança organizacional: da redução conceitual às lições empíricas. In: ENCONTRO NACIONAL DOS PROGRAMAS DE PÓS-GRADUAÇÃO EM ADMINISTRAÇÃO - ENANPAD, 26., 2002, Rio de Janeiro. Anais... Rio de Janeiro: ANPAD, 2002. CD Room.

ROBBINS, Stephen. Administração: mudanças e perspectivas. São Paulo: Saraiva, 2000. RUEKERT, Robert; WALKER, Orville. Marketing's interactions with other functional units: a conceptual framework and empirical evidence. Journal of Marketing, Chicago, v. 5I, n. I, p. I-I9, Jan. I987.

SCHRAMM, Wilbur. The nature of communication between humans. In: SCHRAMM, W.; ROBERTS, D. The process and effects of communication. Urbana: University of Illinois. I97I.

SHANNON, C.; WEAVER, W. The mathematical theory communication. Urbana: University of Illinois, I96I.

SHAPIRO, Benson. Can marketing and manufacturing coexist? Harvard Business Review, Boston, v. 55, n. 5, p. I04, I977.

SIMANTOB, Moysés; LIPPI, Roberta. Guia do valor econômico e inovação nas empresas. São Paulo: Globo, 2002.

SMITH, Preston; REINERTSEN, Donald. Desenvolvendo produtos na metade do tempo: a agilidade como fator decisivo diante da globalização do mercado. São Paulo: Futura, I997.

THAYER, Lee. Comunicação: fundamentos e sistemas na organização, na administração, nas relações interpessoais. São Paulo: Atlas, ı976.

TRIVIÑOS, Augusto Nibaldo Silva. Bases teórico-metodológicas da pesquisa qualitativa em ciências sociais. 2 ed. Porto Alegre: Ritter dos Reis, I987. (Caderno de Pesquisa Ritter dos Reis, v. IV). 
WOLF, Mauro. Teorias da comunicação. 7. ed. Lisboa: Presença, 2002.

YIN, Robert. Estudo de caso: planejamento e métodos. 2. ed. Porto Alegre: Bookman, 200I.

TRAMITAÇ ÃO

Recebido em 30/3/2006

Aprovado em 24/4/2006 
Copyright of Revista de Administração Mackenzie is the property of Universidade Presbiteriana Mackenzie, RAM-Revista de Administracao Mackenzie and its content may not be copied or emailed to multiple sites or posted to a listserv without the copyright holder's express written permission. However, users may print, download, or email articles for individual use. 